\title{
Simultaneous Synthesis and Design of Reaction-Separation-Recycle Processes using Rigorous Models
}

Yingjie Ma, ${ }^{1}$ Zekun Yang, ${ }^{1}$ Aline El-Khoruy, ${ }^{1}$ Nan Zhang, ${ }^{1}$ Jie Li,${ }^{1,}$ Bingjian Zhang, ${ }^{2}$ Li Sun ${ }^{3}$

${ }^{1}$ Centre for Process Integration, Department of Chemical Engineering and Analytical Science, School of Engineering, The University of Manchester, Manchester M13 9PL, UK

${ }^{2}$ School of Materials Science and Engineering, Guangdong Engineering Technology Research Center for Petrochemical Energy Conservation, Sun Yat-sen University, Guangzhou, 510275, China ${ }^{3}$ School of Computing, Engineering and Physical Sciences, The University of the West of Scotland, Scotland PA1 2BE, UK

\section{List of Tables}

Table S1) Parameters and Specifications in the case study 1; Table S2) Parameters for component physical properties in the case study 1; Table S3) Steam used in different equipment in the case study 1; Table S4) Parameters and specifications in the case study 2; Table S5) Parameters for component physical properties in the case study 2; Table S6) Parameters for Wilson equations; Table S7) Feedstock and product specification and price; Table S8) Utility prices for HDA process; Table S9) Investment costs for HDA process; (Table S10) Parameters for Antoine equation; (Table S11) Parameters for ideal vapour heat capacity polynomial; (Table S12) Parameters for DIPPR liquid heat capacity polynomial; (Table S13) Number of binary variables required for separation of a mixture with different numbers of components in the two SEN representations;

\section{List of Figures}

Figure S1 Reactions in benzene chlorination process

Figure S2 Reaction pathway for cyclohexane oxidation

Figure S3 Superstructure for the cyclohexane oxidation process

Figure S4 Reactions in the HDA process

\footnotetext{
* Corresponding author: Jie Li (Email address: jie.li-2@manchester.ac.uk). Tel: + 44 (0) 161306 8622. Fax: +44 (0) 161 2367439
} 


\section{S1 Reactor models}

In this work, $\mathbf{R}=\left\{c s t r, p f r_{-} i s o, p f r_{-} a d b\right.$, bypass $\}$ is used to represent the set of four reactor types including CSTR, isothermal PFR, adiabatic PFR and bypass stream. There are $M(m=1,2,3, \ldots, M)$ reactions.

For CSTR, we have

$F_{i, r, k}^{\text {out }}=F_{i, r, k}^{\text {in }}+\tau_{r, k} \cdot \sum_{m}\left[v_{i, m} \cdot\right.$ Rate $\left._{m}\left(X_{i, r, k}^{\text {out }}, T_{r, k}^{r e a c}\right)\right]$

$$
\forall k \in \mathbf{K}^{R}, i, r=c s t r
$$

$\sum_{i}\left(F_{i, r, k}^{\text {out }} \cdot h_{i, k}^{\text {out }}\right)=\sum_{i}\left(F_{i, r, k}^{\text {in }} \cdot h_{i, k}^{\text {in }}\right)-\sum_{m}\left(\xi_{m, r, k} \cdot \Delta H r_{m}\right)-Q_{r, k}$

$T_{r, k}^{r e a c}=T_{k}^{\text {out }}$

$\forall k \in \mathbf{K}^{R}, r=c s t r$

$\forall k \in \mathbf{K}^{R}, r=c s t r$

Here, $F_{i, r, k}^{i n}$ and $F_{i, r, k}^{o u t}$ are the flow rate of component $i$ entering and leaving reactor type $r$ in stage k. Rate $_{m}$ is the reaction rate of reaction, which is calculated from the outlet concentration $\left(X_{i, r, k}^{\text {out }}\right)$ and reaction temperature $\left(T_{r, k}^{r e a c}\right)$. As shown in Eq. (S3), for CSTR reactor, reaction temperature is equal to the actual outlet temperature instead of disaggregated outlet temperature to avoid a reaction temperature becomes 0 because the reaction temperature usually appears in the denominator of reaction rate constant calculation equation. The outlet concentration can be calculated from the disaggregated outlet flow rates of CSTR. $v_{i, m}$ is the stoichiometric coefficient of component $i$ in reaction $m . \Delta H r_{m}$ is the reaction heat of reaction $m$ (exothermic reaction corresponds to negative $\left.\Delta H r_{m}\right) . \xi_{m, r, k}$ is the extent of reaction, which can be calculated from $F_{i, r, k}^{\text {in }}$ and $F_{i, r, k}^{\text {out }} . h_{i, k}^{\text {in }}$ and $h_{i, k}^{\text {out }}$ denote the enthalpies of inlet and outlet streams of the reaction unit $k$ respectively, which are got from corresponding physical property equations. Here, the enthalpies do not include the component formation enthalpy, otherwise, the enthalpy balance equation should exclude the term related with reaction heat. $Q_{r, k}$ is the heat drawn from the reactor $r$ in stage $k$.

We define a subset PFR $=\left\{p f r_{-} i s o, p f r_{-} a d b\right\}$, to represent both isothermal PFR and adiabatic PFR. For PFR with analytically integrable kinetic equations, we have

$$
\begin{array}{ll}
F_{i, r, k}^{\text {out }}=\operatorname{IntR} f\left(F_{i, r, k}^{\text {out }}, T_{r, k}^{\text {reac }}, \tau_{r, k}\right) & \forall k \in \mathbf{K}^{\mathbf{R}}, i, r \in \mathbf{P F R} \\
\sum_{i}\left(F_{i, r, k}^{\text {out }} \cdot h_{i, k}^{\text {out }}\right)=\sum_{i}\left(F_{i, r, k}^{\text {in }} \cdot h_{i, k}^{\text {in }}\right)-\sum_{j}\left(\xi_{j, r, k} \cdot \Delta H r_{j}\right)-Q_{r, k} &
\end{array}
$$

$$
\forall k \in \mathbf{K}^{\mathbf{R}}, r \in \mathbf{P F R}
$$

Here, IntRf represents the kinetic equations after integration, and $T_{k}^{r e a c}$ denotes the reaction temperature. The other symbols have the same meaning as those in Eqs. (S1-S3). 
For isothermal PFR, $T_{r, k}^{r e a c}$ is equal to the outlet temperature, i.e.,

$$
T_{r, k}^{\text {reac }}=T_{k}^{\text {out }} \quad \forall k \in \mathbf{K}^{R}, r=p f r_{-} \text {iso }
$$

For adiabatic PFR, $Q_{r, k}$ is fixed to be 0 and $T_{k}^{r e a c}$ is approximated as the average of the inlet and outlet temperatures ${ }^{1}$. In other words,

$Q_{r, k}=0$

$$
\begin{aligned}
& k \in \mathbf{K}^{\boldsymbol{R}}, r=p f r_{-} a d b \\
& \forall k \in \mathbf{K}^{\boldsymbol{R}}, r=p f r_{-} a d b
\end{aligned}
$$$$
T_{r, k}^{r e a c}=\frac{T_{k}^{i n}+T_{k}^{o u t}}{2}
$$

For a bypass stream,

$F_{i, r, k}^{\text {out }}=F_{i, r, k}^{\text {in }}$

$\forall k \in \mathbf{K}^{R}, i, r=$ bypass

$h_{i, k}^{\text {out }}=h_{i, k}^{\text {in }}$

$\forall k \in \mathbf{K}^{\mathbf{R}}, r=$ bypass

$Q_{r, k}=0$

$k \in \mathbf{K}^{\boldsymbol{R}}, r=$ bypass

$T_{r, k}^{r e a c}=T_{k}^{o u t}$

$\forall k \in \mathbf{K}^{R}, r=$ bypass

$\tau_{r, k}=0$

$\forall k \in \mathbf{K}^{\boldsymbol{R}}, r=$ bypass

The capital cost for a reactor is calculated as followings:

$\operatorname{Cap}_{r, k}=y_{r, k} \cdot$ Fix $_{r}+C^{r}\left(\tau_{r, k}\right)$

$\forall k \in \mathbf{K}^{R}, r$

Here, Fix $r$ is the fixed cost, which is a constant and can be different for different reactor types. For the bypass stream, Fix $_{r}=0 . C C^{r}(\cdot)$ is a function calculating material costs for different reactor types. $y_{r, k}$ is a binary variable denoting whether is reactor type $r$ is selected or not at a stage $k$.

\section{S2 Modelling distillation sequence for quaternary separation}

As shown in Fig. 2b, the column 1 may perform three different tasks A/BCD, A/BC or A/B with A and $B$ as the key components. Therefore, $\mathbf{D}_{1}=\{\mathrm{A} / \mathrm{BCD}, \mathrm{A} / \mathrm{BC}, \mathrm{A} / \mathrm{B}\}$. Similarly, $\mathbf{D}_{2}=\{\mathrm{AB} / \mathrm{CD}, \mathrm{AB} / \mathrm{C}$, $\mathrm{B} / \mathrm{CD}, \mathrm{B} / \mathrm{C}\}$ and $\mathbf{D}_{3}=\{\mathrm{ABC} / \mathrm{D}, \mathrm{BC} / \mathrm{D}, \mathrm{C} / \mathrm{D}\}$. The separation tasks obtaining component $\mathrm{A}$ from distillate belonging to $\mathbf{D D} \mathbf{p}_{\mathrm{A}}=\{\mathrm{A} / \mathrm{B}, \mathrm{A} / \mathrm{BC}, \mathrm{A} / \mathrm{BCD}\}$. Similarly, $\mathbf{D D} \mathbf{p}_{\mathrm{B}}=\{\mathrm{B} / \mathrm{C}, \mathrm{B} / \mathrm{CD}\}, \mathbf{D D P} \mathbf{P}_{\mathrm{C}}=$ $\{\mathrm{C} / \mathrm{D}\}$, and $\mathbf{D D P} \mathbf{P}_{\mathrm{D}}=\emptyset, \mathbf{D B} \mathbf{p}_{\mathrm{A}}=\emptyset, \mathbf{D B P} \mathbf{P}_{\mathrm{B}}=\{\mathrm{A} / \mathrm{B}\}, \mathbf{D B P} \mathbf{P}_{\mathrm{C}}=\{\mathrm{B} / \mathrm{C}, \mathrm{AB} / \mathrm{C}\}, \mathbf{D B} \mathbf{P}_{\mathrm{D}}=\{\mathrm{C} / \mathrm{D}, \mathrm{BC} / \mathrm{D}$, $\mathrm{ABC} / \mathrm{D}\}$. The separation tasks taking component $\mathrm{A}$ as light key component belonging to $\mathbf{D D} \mathbf{k}_{\mathrm{A}}=$ $\{\mathrm{A} / \mathrm{B}, \mathrm{A} / \mathrm{BC}, \mathrm{A} / \mathrm{BCD}\}$. Similarly, $\mathbf{D D k}_{\mathrm{B}}=\{\mathrm{B} / \mathrm{C}, \mathrm{AB} / \mathrm{C}, \mathrm{B} / \mathrm{CD}, \mathrm{AB} / \mathrm{CD}\}, \mathbf{D D k} \mathbf{k}_{\mathrm{C}}=\{\mathrm{C} / \mathrm{D}, \mathrm{BC} / \mathrm{D}$, $\mathrm{ABC} / \mathrm{D}\}, \mathbf{D D k}_{\mathrm{D}}=\emptyset, \mathbf{D B} \mathbf{k}_{\mathrm{A}}=\emptyset, \mathbf{D B} \mathbf{k}_{\mathrm{B}}=\{\mathrm{A} / \mathrm{B}, \mathrm{A} / \mathrm{BC}, \mathrm{A} / \mathrm{BCD}\}, \mathbf{D B} \mathbf{k}_{\mathrm{C}}=\{\mathrm{B} / \mathrm{C}, \mathrm{AB} / \mathrm{C}, \mathrm{B} / \mathrm{CD}$, $\mathrm{AB} / \mathrm{CD}\}, \mathbf{D B k}_{\mathrm{D}}=\{\mathrm{C} / \mathrm{D}, \mathrm{BC} / \mathrm{D}, \mathrm{ABC} / \mathrm{D}\}$.

Consider Eqs. (27-30) in the main manuscript, when $j=1$ and $i=\mathrm{A}, \mathbf{D}_{j} \cap \mathbf{D D} \mathbf{p}_{i}=\{\mathrm{A} / \mathrm{BCD}, \mathrm{A} / \mathrm{BC}$, $\mathrm{A} / \mathrm{B}\}, \mathbf{D}_{j} \cap \mathbf{D D k}_{i}=\{\mathrm{A} / \mathrm{BCD}, \mathrm{A} / \mathrm{BC}, \mathrm{A} / \mathrm{B}\}, \mathbf{D}_{j} \cap \mathbf{D B} \mathbf{p}_{i}=\emptyset, \mathbf{D}_{j} \cap \mathbf{D B k}_{i}=\emptyset$. Thus, we have:

$x D_{1}^{A} \geq y_{A / B C D} \cdot \xi^{A}, \quad x D_{1}^{A} \geq y_{A / B C} \cdot \xi^{A}, \quad x D_{1}^{A} \geq y_{A / B} \cdot \xi^{A}$,

$s D_{1}^{A} \geq y_{A / B C D} \cdot \varphi^{A}, \quad s D_{1}^{A} \geq y_{A / B C} \cdot \varphi^{A}, \quad s D_{1}^{A} \geq y_{A / B} \cdot \varphi^{A}$.

When $j=1$ and $i=\mathrm{B}, \mathbf{D}_{j} \cap \mathbf{D D} \mathbf{p}_{i}=\emptyset, \mathbf{D}_{j} \cap \mathbf{D D} \mathbf{k}_{i}=\emptyset, \mathbf{D}_{j} \cap \mathbf{D B} \mathbf{p}_{i}=\{\mathrm{A} / \mathrm{B}\}, \mathbf{D}_{j} \cap \mathbf{D B k}_{i}=\{\mathrm{A} / \mathrm{B}, \mathrm{A} / \mathrm{BC}$, 
$\mathrm{A} / \mathrm{BCD}\}$. Thus, we have

$x B_{1}^{B} \geq y_{A / B} \cdot \xi^{B}, \quad s B_{1}^{B} \geq y_{A / B C D} \cdot \varphi^{B}, \quad s B_{1}^{B} \geq y_{A / B C} \cdot \varphi^{B}, \quad s B_{1}^{B} \geq y_{A / B} \cdot \varphi^{B}$

When $j=1$ and $i=\mathrm{C}$ or $\mathbf{D}, \mathbf{D}_{j} \cap \mathbf{D D} \mathbf{p}_{i}=\emptyset, \mathbf{D}_{j} \cap \mathbf{D D k}_{i}=\emptyset, \mathbf{D}_{j} \cap \mathbf{D B} \mathbf{p}_{i}=\emptyset, \mathbf{D}_{j} \cap \mathbf{D B} \mathbf{k}_{i}=\varnothing$. Thus, no constraints are required in such case.

According to Eq. (26) in the main manuscript, we have

$$
y_{A / B C D}+y_{A / B C}+y_{A / B}=1
$$

With Eq. (S17), the Eqs. (S15 - S16) can be simplified as Eqs. (S18 - S19) respectively,

$$
\begin{array}{ll}
x D_{1}^{A} \geq \xi^{A} & s D_{1}^{A} \geq \varphi^{A} \\
x D_{1}^{B} \geq y_{A / B} \cdot \xi^{B} & s B_{1}^{B} \geq \varphi^{B} .
\end{array}
$$

Similarly, we get the constraints for columns 2, Eqs. (S20 - S22),

$$
\begin{array}{lll}
x D_{2}^{B} \geq y_{B / C} \cdot \xi^{B}, & x D_{2}^{B} \geq y_{B / C D} \cdot \xi^{B}, & s D_{2}^{B} \geq y_{B / C} \cdot \varphi^{B}, \\
s D_{2}^{B} \geq y_{A B / C} \cdot \varphi^{B}, & s D_{2}^{B} \geq y_{B / C D} \cdot \varphi^{B}, & s D_{2}^{B} \geq y_{A B / C D} \cdot \varphi^{B}, \\
x B_{2}^{C} \geq y_{B / C} \cdot \xi^{C}, & x B_{2}^{C} \geq y_{A B / C} \cdot \xi^{C}, & s B_{2}^{C} \geq y_{B / C} \cdot \varphi^{C}, \\
s B_{2}^{C} \geq y_{A B / C} \cdot \varphi^{C}, & s B_{2}^{C} \geq y_{B / C D} \cdot \varphi^{C}, & s B_{2}^{C} \geq y_{A B / C D} \cdot \varphi^{C} . \\
y_{A B / C D}+y_{A B / C}+y_{B / C D}+y_{B / C}=1 . &
\end{array}
$$

After simplifying Eqs. (S20-S21) through applying Eq. (S22), we get

$$
\begin{array}{ll}
x B_{2}^{B} \geq\left(y_{B / C}+y_{B / C D}\right) \xi^{B}, & s_{2}^{B} \geq \varphi^{B} . \\
x B_{2}^{C} \geq\left(y_{A B / C}+y_{B / C}\right) \xi^{C}, & s_{2}^{C} \geq \varphi^{C} .
\end{array}
$$

Similarly, the constraints for column 3 are Eqs. (S25-S27),

$$
\begin{array}{lll}
x D_{3}^{C} \geq y_{C / D} \cdot \xi^{C}, & s D_{3}^{C} \geq y_{C / D} \cdot \varphi^{C}, & s D_{3}^{C} \geq y_{B C / D} \cdot \varphi^{C}, \\
s D_{3}^{C} \geq y_{A B C / D} \cdot \varphi^{C}, & \\
x B_{3}^{D} \geq y_{C / D} \cdot \xi^{D}, & x B_{3}^{D} \geq y_{B C / D} \cdot \xi^{D}, & x B_{3}^{D} \geq y_{A B C / D} \cdot \xi^{D}, \\
s B_{3}^{D} \geq y_{C / D} \cdot \varphi^{D}, & s B_{3}^{D} \geq y_{B C / D} \cdot \varphi^{D}, & s B_{3}^{D} \geq y_{A B C / D} \cdot \varphi^{D} . \\
y_{A B C / D}+y_{B C / D}+y_{C / D}=1 &
\end{array}
$$

After simplification, we get

$$
\begin{array}{ll}
x D_{3}^{C} \geq y_{C / D} \xi^{C} & s D_{3}^{C} \geq \varphi^{C} \\
x B_{3}^{D} \geq \xi^{D} & s B_{3}^{D} \geq \varphi^{D} .
\end{array}
$$

Consider the logical constraints in Eqs. (31-32) in main manuscript, for column $j=1$, start component $i_{s}=\mathrm{A}$, light key component $i_{k}=\mathrm{A}$, and end component $i_{e}=\mathrm{D}$, we have $d\left(i_{s}, i_{k}, i_{e}, j\right)=\mathrm{A} / \mathrm{BCD}$. Thus, there is no $k_{1}$ satisfying $s \leqslant k_{1}<k$, while the possible $k_{2}$ are 2 and 3 . This leads to the first inequality in Eq. (S30). The other equations corresponding to Eqs. (31-32) can be got similarly, which are also shown in Eq. (S30). 
$Y_{B / C D}+Y_{B C / D} \geq Y_{A / B C D}, Y_{A / B} \geq Y_{A B / C D}, Y_{C / D} \geq Y_{A B / C D}, Y_{A / B C}+Y_{A B / C} \geq Y_{A B C / D}$

$Y_{C / D} \geq Y_{B / C D}, Y_{B / C} \geq Y_{B C / D}, Y_{B / C} \geq Y_{A / B C}, Y_{A / B} \geq Y_{A B / C}$.

Consider logical constraint Eq. (33) in the main manuscript, for column $j=1$, start component $i_{s}=\mathrm{A}$, light key component $i_{k}=\mathrm{A}$, and end component $i_{e}=\mathrm{B}$, we have $d\left(i_{s}, i_{k}, i_{e}, j\right)=\mathrm{A} / \mathrm{B}$. Thus, there is no $k_{3}$ satisfying $1 \leqslant k_{3}<s-1=0$, while the possible $k_{4}$ are 3 and 4 . This leads to the first inequality in Eq. (S31). The other equations corresponding to Eq. (33) can be got similarly, which are also shown in Eq. (S31).

$$
\begin{aligned}
Y_{A B / C}+Y_{A B / C D} \geq Y_{A / B}, Y_{A / B C}+Y_{B C / D} \geq Y_{B / C}, Y_{B / C D}+Y_{A B / C D} \geq Y_{C / D} \\
Y_{A B C / D} \geq Y_{A B / C}, Y_{A B C / D} \geq Y_{A / B C}, Y_{A / B C D} \geq Y_{B / C D}, Y_{A / B C D} \geq Y_{B C / D}
\end{aligned}
$$

\section{S3 Total annualized cost model for case studies 1 and 2}

The total annualized cost (TAC) model is from Zhang et al., ${ }^{2}$ which includes total operation cost (TOC) and total capital cost (TCC) with a payback period 1 year, i.e.,

$T A C=T O C+1 \cdot T C C$,

where $T A C, T O C$ and $T C C$ are all in the unit of $€$ year ${ }^{-1}$.

TOC is composed of the costs of cooling water and steam with prices of $5 \times 10^{-5} € \mathrm{~kg}^{-1}$ and $1 \times 10^{-}$ ${ }^{2} € / \mathrm{kg}^{-1}$ respectively, so

TOC $=5 \times 10^{-5} m_{C W}+1 \times 10^{-2} m_{S T}$,

where $m_{C W}\left(\mathrm{~kg} \mathrm{~s}^{-1}\right)$ and $m_{S T}\left(\mathrm{~kg} \mathrm{~s}^{-1}\right)$ are the mass flow rates of cooling water and steam respectively. The flow rates of utilities are got from their heat duties $Q_{\text {cond }}(\mathrm{kW})$ and $Q_{r e b}(\mathrm{~kW})$ by Eqs. (S34S35),

$m_{C W}=\frac{Q_{c o n d}}{C p_{C W}\left(T_{C W}^{\text {out }}-T_{C W}^{i n}\right)}$,

$m_{S T}=\frac{Q_{\text {reb }}}{\Delta H_{\text {vap }}}$,

where $C p_{C W}$ is the mass-based heat capacity of water $\left(4.18 \mathrm{~kJ} \mathrm{~kg}^{-1} \mathrm{~K}^{-1}\right) \cdot T_{\text {cond }}$ is the temperature of the condenser derived from MESH equations, while $T_{C W}^{i n}$ and $T_{C W}^{o u t}$ are inlet and outlet temperatures of cooling water respectively, which are $293.15 \mathrm{~K}$ and $343.15 \mathrm{~K}$ respectively. $\Delta H_{\text {vap }}$ $\left(\mathrm{kJ} \mathrm{kg}^{-1}\right)$ is the vaporization enthalpy of the steam used for heating, the values of which will be given in the following parts for each specific steam.

TCC comprises the capital costs of reactors, heat exchangers and distillation columns.

\section{S3.1 Capital cost of reactors}

The capital cost of a reactor $C_{\text {reac }}^{n}\left(€\right.$ year $\left.{ }^{-1}\right)$ is 
$C_{\text {reac }}^{n}=1000\left(\frac{D_{n}}{0.9144}\right)^{1.05}\left(\frac{L_{n}}{1.2192}\right)^{0.81}$,

where $D_{n}(\mathrm{~m})$ and $L_{n}(\mathrm{~m})$ are the diameters and lengths of the reactor respectively. It is assumed that the length of the reactor is four times its diameter, so we have

$D_{n}=\sqrt[3]{\frac{V_{n}}{\pi}}$

and

$L_{n}=4 D_{n}$.

The reactor volume $V_{n}\left(\mathrm{~m}^{3}\right)$ is got from

$V_{n}=\dot{V}_{n} \tau_{n}$

where $\dot{V}_{n}$ is the inlet volume flow rate of the reactor $\left(\mathrm{m}^{3} \mathrm{~s}^{-1}\right)$ and $\tau_{n}$ is the residence time (s).

The total capital cost of $N$ reactors, $C_{r t}\left(€\right.$ year $\left.^{-1}\right)$ is

$C_{r t}=\sum_{n=1}^{N} \frac{0.75 \times 585 \times 4.23}{115} C_{r e a c}^{n}$.

\section{S3.2 Capital cost of heat exchangers}

The cost of a heat exchanger, $C_{h x}\left(€\right.$ year $\left.^{-1}\right)$ is

$C_{h x}=3100 A_{h x}^{0.65}$,

where $A_{h x}\left(\mathrm{~m}^{2}\right)$ is the area of the heat exchanger. The area is got from

$A_{h x}=\frac{\left|Q_{h x}\right|}{U \Delta \bar{T}}$

where $Q_{h x}(\mathrm{~kW})$ is the heat duty of the heat exchanger, $U$ is the heat transfer coefficient $(0.8$ $\left.\mathrm{kW} / \mathrm{m}^{2} / \mathrm{K}\right)$, and $\Delta \bar{T}(\mathrm{~K})$ is the logarithmic mean temperature difference (LMTD) of the heat exchanger.

\section{S3.3 Capital cost of distillation columns}

The capital cost of a distillation column $\left(C_{c o l}\right)$ includes the cost of column shell $\left(C_{\text {shell }}\right)$, the cost of column internals $\left(C_{\text {inter }}\right)$, reboiler cost $\left(C_{\text {reb }}\right)$ and condenser cost $\left(C_{\text {cond }}\right)$, which are all in the unit of $€$ year $^{-1}$. Hence,

$C_{\text {col }}=C_{\text {shell }}+C_{\text {inter }}+C_{\text {reb }}+C_{\text {cond }}$,

where

$C_{\text {shell }}=4100 D_{\text {col }} \cdot H_{\text {col }}$

and

$C_{\text {inter }}=1800 \mathrm{NT} \cdot D_{\text {col }} h$.

Here, $D_{c o l}(\mathrm{~m}), H_{c o l}(\mathrm{~m}), N T$ and $h(\mathrm{~m})$ are the diameter of the column, height of the column, total number of stages and stage space respectively. $h$ is $0.5 \mathrm{~m}$ in this work.

$H_{c o l}=N T \cdot h+4$,

and 
$D_{\text {col }}=\sqrt{\frac{4 \dot{V}_{b}}{2 \pi} \sqrt{\frac{R T_{b}\left(\sum_{i} y^{i} M^{i}\right)}{P}}}$.

Here, $\dot{V}_{b}\left(\mathrm{~m}^{3} \mathrm{~s}^{-1}\right)$ is the volume flow rate at the bottom stage, $R\left(8.314 \mathrm{~kJ} \mathrm{kmol}^{-1} \mathrm{~K}^{-1}\right)$ is the ideal gas constant, $T_{b}(\mathrm{~K})$ is the temperature at the bottom stage, and $P(\mathrm{~Pa})$ is the pressure at the bottom stage. $y^{i}\left(\mathrm{kmol} \mathrm{kmol}^{-1}\right)$ and $M^{i}\left(\mathrm{~kg} \mathrm{kmol}^{-1}\right)$ are the mole fraction and molecular weight of a component $i$ respectively.

The total capital cost of reboiler and condenser is

$C_{\text {reb }}+C_{\text {cond }}=3100\left(A_{\text {reb }}+A_{\text {cond }}\right)^{0.65}$,

where $A_{r e b}\left(\mathrm{~m}^{2}\right)$ and $A_{\text {cond }}\left(\mathrm{m}^{2}\right)$ are the areas of reboiler and condenser respectively.

$A_{\text {reb }}=\frac{Q_{\text {reb }}}{U \Delta T_{r e b}}$

and

$A_{\text {cond }}=\frac{Q_{\text {cond }}}{U \Delta T_{\text {cond }}}$

where $Q_{\text {reb }}(\mathrm{kW})$ and $Q_{\text {cond }}(\mathrm{kW})$ are the heat duties of reboiler and condenser respectively. $\Delta T_{\text {reb }}$ $(\mathrm{K})$ and $\Delta T_{\text {cond }}(\mathrm{K})$ are the LMTD of the reboiler and condenser respectively.

\section{S4 Parameters of reactions and physical properties for case study 1}

The reactions for benzene chlorination is as Fig. S1.<smiles>CC(Cl)(c1ccccc1)c1ccc(Cl)cc1Cl</smiles>

Figure S1 Reactions in benzene chlorination process

All the reactions are first-order reactions, and the kinetic constants and operating conditions for the reactions are shown in Table S1. To get the reaction rates, the kinetic constants are multiplied with the molar concentration of benzene and chlorobenzene respectively for the two reactions. Some specification conditions for distillation columns are also given in Table S1.

Table S1 Parameters and Specifications in the case study 1

\begin{tabular}{ll}
\hline \multicolumn{2}{l}{ Reactor } \\
\hline$k_{1}$ & $0.412 \mathrm{~h}^{-1}$ \\
$k_{2}$ & $0.055 \mathrm{~h}^{-1}$ \\
Reaction temperature & $30{ }^{\circ} \mathrm{C}$ \\
Reaction pressure & $1 \mathrm{~atm}$
\end{tabular}




\section{Distillation column}

Operating pressure

Upper bound of the number of trays

Initial feed location (top to bottom)
$1 \mathrm{~atm}$

13

The enthalpy in the process is calculated by

$h_{L}^{i}=h_{f, L}^{i}+C p_{L}^{i}\left(T-T_{0}\right)$,

$h_{V}^{i}=h_{f, G}^{i}+C p_{V}^{i}\left(T-T_{0}\right)$,

where $h_{f, L}^{i}$ and $h_{f, V}^{i}$ are the liquid and vapour standard formation enthalpies respectively, which are shown in Table $\mathrm{S} 2 . C p_{L}^{i}$ and $C p_{V}^{i}$ are mass-based specific heat capacities for liquid and vapour respectively, which are also shown in Table $\mathrm{S} 2 . T_{0}$ is the reference temperature for the enthalpy, which is $273.15 \mathrm{~K} . T(\mathrm{~K})$ is the temperature of the stream in the process.

Table S2 Parameters for component physical properties in the case study 1

\begin{tabular}{llll}
\hline & Benzene & chlorobenzene & dichlorobenzene \\
\hline Molecular weight $\left(\mathrm{kg} \mathrm{kmol}^{-1}\right)$ & 78.11 & 112.56 & 147.01 \\
$\begin{array}{l}\text { Density }\left(\mathrm{kg} \mathrm{m}^{-3}\right) \\
\text { Vapour standard formation enthalpy }\end{array}$ & 876 & 1110 & 1300 \\
$\left(\mathrm{~kJ} \mathrm{kmol}^{-1}\right)$ & 82900 & 520000 & 33000 \\
Liquid standard formation enthalpy & 48700 & 11100 & -17400 \\
$(\mathrm{~kJ} \mathrm{kmol}$ & & \\
Vapour heat capacity $\left(\mathrm{kJ} \mathrm{kmol}^{-1} \mathrm{~K}^{-1}\right)$ & 94 & 108 & 118 \\
Liquid heat capacity $(\mathrm{kJ} \mathrm{kmol}$ & & \\
Antoine coefficient A & 134 & 161 & 193 \\
Antoine coefficient B & 13.78 & 13.86 & 14.26 \\
Antoine coefficient C & 2726.81 & 3174.78 & 3798.20 \\
\hline
\end{tabular}

The saturate pressure of each component is got from the Antoine equation, as Eq. (S52)

$P_{\text {sat }}^{i}=\exp \left(A^{i}-\frac{B^{i}}{C^{i}+T-T_{0}}\right)$,

where $A^{i}, B^{i}$ and $C^{i}$ are Antoine coefficients for each component, which are shown in Table S2. Three kinds of steam are used in the process, the parameters of which are shown in Table S3. 
Table S3 Steam used in different equipment in the case study 1

\begin{tabular}{llll}
\hline & Preheater & Column 1 & Column 2 \\
\hline Temperature $(\mathrm{K})$ & 425 & 450 & 474.5 \\
Vaporization enthalpy $\left(\mathrm{kJ} \mathrm{kg}^{-1}\right)$ & 2107.42 & 2021.4 & 1933.19 \\
\hline
\end{tabular}

\section{S5 Parameters of reactions and physical properties for case study 2}

The reactions in the cyclohexane oxidation are shown in Fig. S2.

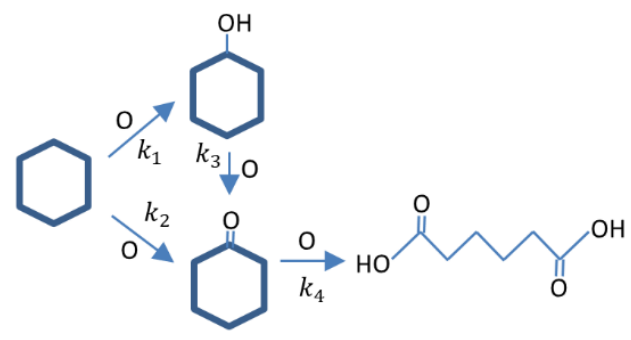

Figure S2 Reaction pathway for cyclohexane oxidation

All the reactions are first-order reactions, the kinetic constants and operating conditions for reactions are shown in Table S4. To get the reaction rates, the kinetic constants are multiplied with the molar concentration of cyclohexane, cyclohexane, cyclohexanol and cyclohexanone respectively for the four reactions. Some specification conditions for distillation columns are also given in Table S4.

Table S4 Parameters and specifications in the case study 2

\begin{tabular}{ll}
\hline \multicolumn{2}{c}{ Reactor } \\
\hline$k_{1}$ & $0.12 \mathrm{~h}^{-1}$ \\
$k_{2}$ & $0.032 \mathrm{~h}^{-1}$ \\
$k_{3}$ & $2.85 \mathrm{~h}^{-1}$ \\
$k_{4}$ & $2.30 \mathrm{~h}^{-1}$ \\
Reaction temperature & $160{ }^{\circ} \mathrm{C}$ \\
Reaction pressure & $10 \mathrm{~atm}$ \\
Chlorobenzene product rate & $50 \mathrm{kmol} \mathrm{h}^{-1}$ \\
& \\
Operating pressure & $1 \mathrm{~atm}$ \\
Upper bound of the number of trays & 25 \\
Initial feed location (top to bottom) & 13 \\
\hline
\end{tabular}

The parameters for the physical properties of pure components are shown in Table S5, 
Table S5 Parameters for component physical properties in the case study 2

\begin{tabular}{|c|c|c|c|c|}
\hline & Cyclohexane & Cyclohexanone & Cyclohexanol & Adipic acid \\
\hline Molecular weight $\left(\mathrm{kg} \mathrm{kmol}^{-1}\right)$ & 84.2 & 98.1 & 100.2 & 337.5 \\
\hline Density $\left(\mathrm{kg} \mathrm{m}^{-3}\right)$ & 778 & 948 & 962 & 1360 \\
\hline $\begin{array}{l}\text { Vapour standard formation } \\
\text { enthalpy }\left(\mathrm{kJ} \mathrm{kmol}^{-1}\right)\end{array}$ & -123100 & -231100 & -29000 & -659400 \\
\hline $\begin{array}{l}\text { Liquid standard formation } \\
\text { enthalpy }\left(\mathrm{kJ} \mathrm{kmol}^{-1}\right)\end{array}$ & -156400 & -276100 & -352000 & -741300 \\
\hline $\begin{array}{l}\text { Vapour heat capacity }(\mathrm{kJ} \\
\left.\mathrm{kmol}^{-1} \mathrm{~K}^{-1}\right)\end{array}$ & 105 & 161 & 176 & 245 \\
\hline $\begin{array}{l}\text { Liquid heat capacity }\left(\mathrm{kJ} \mathrm{kmol}^{-}\right. \\
\left.{ }^{1} \mathrm{~K}^{-1}\right)\end{array}$ & 156 & 177 & 214 & 330 \\
\hline Antoine coefficient A & 13.74 & 12.39 & 14.05 & 17.21 \\
\hline Antoine coefficient B & 2766.63 & 2101.96 & 3443.70 & 6477.32 \\
\hline Antoine coefficient $\mathrm{C}$ & -50.50 & -164.02 & -63.59 & -95.95 \\
\hline
\end{tabular}

Similar to case study 1 , here, the enthalpy and saturate pressure of each component are also calculated by Eqs. (S50-S52). However, instead of assuming ideal liquid mixture, this case study uses Wilson equation to calculate liquid activity coefficients, which is shown in Eq. S53

$\ln \gamma_{i}=1-\ln \left(\sum_{k=1}^{4} x_{k} \Lambda_{i k}\right)-\sum_{l=1}^{4} \frac{x_{l} \Lambda_{l i}}{\sum_{k=1}^{4} x_{k} \Lambda_{k l}}$,

where $\gamma_{i}$ is the component activity coefficient, $x_{k}$ and $x_{l}$ are molar compositions, and $\Lambda_{i k}, \Lambda_{l i}$ and $\Lambda_{k l}$ are got from

$\Lambda_{i j}=\frac{M V_{j}}{M V_{i}} \exp \left(\frac{\lambda_{i j}-\lambda_{i i}}{R T}\right)$.

Here, the binary coefficients $\lambda_{i j}$ and the molar volume $M V_{i}$ are shown in Table S6.

Table S6 Parameters for Wilson equations

\begin{tabular}{|c|c|c|c|c|c|}
\hline \multirow[t]{2}{*}{ 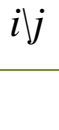 } & & Cyclohexane & Cyclohexanone & Cyclohexanol & Adipic acid \\
\hline & Cyclohexane & 0 & 310.99 & -409.97 & 2576.96 \\
\hline \multirow{2}{*}{$\lambda_{i j}$} & Cyclohexanone & 6074.00 & 0 & 1445.72 & -848.27 \\
\hline & Cyclohexanol & 2560.35 & 357.55 & 0 & -1409.18 \\
\hline & Adipic acid & 9809.50 & 523.97 & 4965.28 & 0 \\
\hline \multicolumn{2}{|c|}{$\operatorname{MV}\left(\mathrm{m}^{3} \mathrm{kmol}^{-1}\right)$} & 0.10816 & 0.10407 & 0.10356 & 0.10746 \\
\hline
\end{tabular}

In this example, the steam temperature is defined to be $30 \mathrm{~K}$ higher than the bubble point of the 
mixture in the reboiler $(\mathrm{LMTD}=30)$, that is $\left(T_{r e b}+30-273.15\right){ }^{\circ} \mathrm{C}$, where $T_{r e b}$ is the temperature in the reboiler, which can be got from MESH equations. Furthermore, the steam latent heat $\Delta H_{v a p}$ is as follows:

$\Delta H_{\text {vap }}=-0.005 \cdot\left(T_{\text {reb }}-243.15\right)^{2}-1.710 \cdot\left(T_{\text {reb }}-243.15\right)+2483.050$,

\section{S6 Model parameters in HDA case study}

\section{S6.1 Cost model}

Table S7 Feedstock and product specification and price for HDA process

\begin{tabular}{lll}
\hline & Specification & Price $\left(\$ \mathrm{kmol}^{-1}\right)$ \\
\hline Hydrogen feed & $95 \%$ hydrogen, & 2.50 \\
& $5 \%$ methane & \\
Toluene feed & $100 \%$ toluene & 14.00 \\
Benzene product & $\geq 99.97 \%$ benzene & 19.90 \\
Diphenyl product & - & 11.84 \\
Hydrogen purge & Heating value & 1.08 \\
Methane purge & Heating value & 3.37 \\
\hline
\end{tabular}

Table S8 Utility prices for HDA process

\begin{tabular}{ll}
\hline & Price \\
\hline Electricity & $0.04 \$(\mathrm{~kW} \cdot \mathrm{h})^{-1}$ \\
Steam & $8.0 \$ \mathrm{GJ}^{-1}$ \\
Water & $0.7 \$ \mathrm{GJ}^{-1}$ \\
Fuel & $4.0 \$ \mathrm{GJ}^{-1}$ \\
\hline
\end{tabular}

Table S9 Investment costs for HDA process

\begin{tabular}{lll}
\hline & $\begin{array}{l}\text { Fixed-charge cost } \\
\left(\mathrm{k} \$ \text { year }^{-1}\right)\end{array}$ & Variable-charge cost $\left(\mathrm{k} \$\right.$ year $\left.{ }^{-1}\right)$ \\
\hline Compressor & 7.155 & $0.815 \times$ brake horsepower $(\mathrm{kW})$ \\
Stabilizing column & 1.126 & $0.375 \times$ number of stages \\
Benzene column & 16.3 & $1.55 \times$ number of stages \\
Toluene column & 3.90 & $1.12 \times$ number of stages \\
Furnace & 6.20 & $1.172 \times$ heat duty $\left(103 \mathrm{GJ} \mathrm{year}^{-1}\right)$ \\
Adiabatic reactor & 74.3 & $1.257 \times$ reactor volume $\left(\mathrm{m}^{3}\right)$ \\
Isothermal reactor & 92.875 & $1.571 \times$ reactor volume $\left(\mathrm{m}^{3}\right)$ \\
\hline
\end{tabular}


In tabel S9, assuming isentropic compression, the compresosr brake horsepower Power is from Eq. (S56)

Power $=\frac{\eta}{\text { eff }} \theta \frac{V_{\text {in }}}{3600} T_{\text {in }}(\alpha-1)$,

$\theta=\frac{C p C v}{C p C v-1}$

$\alpha^{\theta}=\frac{P_{\text {out }}}{P_{\text {in }}}=\frac{T_{\text {out }}}{T_{\text {in }}}$,

where $\eta$ and eff are two constants, which are 0.3665 and 0.75 respectively accroding to the GAMS file provided by Kocis and Grossmann. ${ }^{3} \alpha$ is the compression ratio. $V_{\text {in }}\left(\mathrm{kmol} \mathrm{h}^{-1}\right)$ and $T_{\text {in }}(\mathrm{K})$ are the flow rate and temperature of the inlet stream of the compressor. $P_{\text {in }}(\mathrm{Pa})$ and $P_{\text {out }}(\mathrm{Pa})$ are the inlet and outlet pressures of the compressor respectively and $T_{\text {out }}(\mathrm{K})$ is the outlet temperature. $C p C v$ is the ratio of the heat capacity at constant pressure and heat capacity at constant volume, which is 1.3 in this work.

The heat duty of the furnace can be got from the heat balance between the inlet and outlet stream easily, while the models of distillation columns and reactors are shown in the main text.

\section{S6.2 Saturate vapor pressure calculation}

The Antoine equation is used to calculate the saturate vapor pressure, as shown in Eq. (S59).

$$
\log \left(750 \cdot P_{i}^{S}\right)=A_{i}-\frac{B_{i}}{C_{i}+T} \quad \forall i
$$

where the unit of saturate pressure $P_{i}^{s}$ is bar and the unit of temperature $T$ is $\mathrm{K}$. The parameters are from Kocis and Grossmann ${ }^{1}$ and shown in the following Table S10.

Table S10 Parameters for Antoine equation

\begin{tabular}{llll}
\hline & $\mathrm{A}$ & $\mathrm{B}$ & $\mathrm{C}$ \\
\hline $\mathrm{H}_{2}$ & 13.6333 & 164.9 & 3.19 \\
$\mathrm{CH}_{4}$ & 15.2243 & 897.84 & -7.16 \\
$\mathrm{C}_{6} \mathrm{H}_{6}$ & 15.9008 & 2788.51 & -52.36 \\
$\mathrm{C}_{7} \mathrm{H}_{8}$ & 16.0137 & 3096.52 & -53.67 \\
$\mathrm{C}_{12} \mathrm{H}_{10}$ & 16.6832 & 4602.23 & -70.42 \\
\hline
\end{tabular}

\section{S6.3 Ideal gas heat capacity}

The ideal gas heat capacity of component $i, C_{p}^{i, g}$ is calculated according to Aspen ideal gas heat capacity polynomial, as shown in Eq. (S60).

$C_{p}^{i, g}=C_{g 1}+C_{g 2} T+C_{g 3} T^{2}+C_{g 4} T^{3}+C_{g 5} T^{4}+C_{g 6} T^{5} \quad \forall i$ 
Here, the unit of ideal gas heat capacity $C_{p}^{i, g}$ is $\mathrm{J} \mathrm{kmol}^{-1} \mathrm{~K}^{-1}$ and the unit of temperature is $\mathrm{K}$. The parameters from Aspen Properties V8.8 ${ }^{4}$ are shown in Table S11.

Table S11 Parameters for ideal vapor heat capacity polynomial

\begin{tabular}{lllllll}
\hline & $C_{g 1}$ & $C_{g 2}$ & $C_{g 3}$ & $C_{g 4}$ & $C_{g 5}$ & $C_{g 6}$ \\
\hline $\mathrm{H}_{2}$ & 25555.306 & 14.821 & -0.023 & $1.768 \times 10^{-5}$ & $-5.935 \times 10^{-9}$ & $7.135 \times 10^{-13}$ \\
$\mathrm{CH}_{4}$ & 19250.906 & 52.126 & 0.012 & $-1.132 \times 10^{-5}$ & 0 & 0 \\
$\mathrm{C}_{6} \mathrm{H}_{6}$ & -33917.267 & 474.364 & -0.302 & $7.130 \times 10^{-5}$ & 0 & 0 \\
$\mathrm{C}_{7} \mathrm{H}_{8}$ & -24354.616 & 512.464 & -0.277 & $4.911 \times 10^{-5}$ & 0 & 0 \\
$\mathrm{C}_{12} \mathrm{H}_{10}$ & -97066.771 & 1105.734 & -0.886 & 0.0003 & 0 & 0 \\
\hline
\end{tabular}

\section{S6.4 Liquid heat capacity}

The liquid heat capacity of each component $C_{p}^{i, l}$ is calculated according to DIPPR liquid heat capacity correlation, as shown in Eq. (S61).

$C_{p}^{i, l}=C_{l 1}^{i}+C_{l 2}^{i} T+C_{l 3}^{i} T^{2}+C_{l 4}^{i} T^{3}+C_{l 5}^{i} T^{4} \quad \forall i$

Here, the unit of liquid heat capacity $C_{p}^{i, l}$ is $\mathrm{J} \mathrm{kmol}^{-1} \mathrm{~K}^{-1}$ and the unit of temperature is still $\mathrm{K}$. The parameters from Aspen Properties V8.8 are shown in Table S12. Note that the liquid enthalpies of $\mathrm{H}_{2}$ and $\mathrm{CH}_{4}$ are calculated according to their vapor enthalpies, so the parameters for them are not shown in Table S12.

Table S12 Parameters for DIPPR liquid heat capacity polynomial

\begin{tabular}{llllll}
\hline & $C_{l 1}$ & $C_{l 2}$ & $C_{l 3}$ & $C_{l 4}$ & $C_{l 5}$ \\
\hline $\mathrm{C}_{6} \mathrm{H}_{6}$ & 129440 & -169.5 & 0.648 & 0 & 0 \\
$\mathrm{C}_{7} \mathrm{H}_{8}$ & 140140 & -152.3 & 0.695 & 0 & 0 \\
$\mathrm{C}_{12} \mathrm{H}_{10}$ & 121770 & 429.3 & 0 & 0 & 0 \\
\hline
\end{tabular}

\section{S6.5 Specific enthalpies of vapor and lquid}

The vapor specific enthalpy is calculated from Eq. (S62),

$h_{i}^{g}=h_{i}^{g, 0}+\int_{T_{0}}^{T} C_{p, i}^{*, g} d T$

$\forall i$

Here, $h_{i}^{g, 0}$ and $h_{i}^{g}$ are the vapor specific enthalphies of component $i$ at temperatures $T_{0}$ and $T$ respectively. $T_{0}$ is a referring temperature, which is $300 \mathrm{~K}$ in this work. When the ideal gas heat capacity is calculated from Eq. (S61), Eq. (S62) can be integrated analytically, leading to Eq. (S63), $h_{i}^{g}=h_{i}^{g, 0}+C_{g 1}\left(T-T_{0}\right)+\frac{1}{2} C_{g 2}\left(T^{2}-T_{0}^{2}\right)+\frac{1}{3} C_{g 3}\left(T^{3}-T_{0}{ }^{3}\right)+\frac{1}{4} C_{g 4}\left(T^{4}-T_{0}^{4}\right)+$ $\frac{1}{5} C_{g 5}\left(T^{5}-T_{0}{ }^{5}\right)+\frac{1}{6} C_{g 6}\left(T^{6}-T_{0}{ }^{6}\right) \quad \forall i$ 
The liquid specific enthalpy $h_{i}^{l}$ is calculated from Eq. (S64),

$h_{i}^{l}=h_{i}^{l, 0}+\int_{T_{0}}^{T} C_{p, i}^{*, l} d T$

Here, $h_{i}^{l, 0}$ and $h_{i}^{l}$ are the liquid specific enthalphies of component $i$ at temperatures $T_{0}$ and $T$ respectively.When applying DIPPR liquid heat capacity polynomial, Eq. (S64) can be integrated analytically, resulting in Eq. (S65),

$h_{i}^{l}=h_{i}^{l, 0}+C_{l 1}\left(T-T_{0}\right)+\frac{1}{2} C_{l 2}\left(T^{2}-T_{0}{ }^{2}\right)+\frac{1}{3} C_{l 3}\left(T^{3}-T_{0}{ }^{3}\right)+\frac{1}{4} C_{l 4}\left(T^{4}-T_{0}{ }^{4}\right)+$

$$
\frac{1}{5} C_{l 5}\left(T^{5}-T_{0}{ }^{5}\right) \quad \forall i
$$

In Eqs. (S63) and (S65), both $h_{i}^{g, 0}$ and $h_{i}^{l, 0}$ are got from Aspen Plus V8.8 under reference temperature $T_{0}$, so they have considered the component formation enthalpies. Hence, $h_{i}^{g}$ and $h_{i}^{l}$ also include the component formation enthalpies.

Table S13 Number of binary variables required for separation of a mixture with different numbers of components in the two SEN representations

\begin{tabular}{ccc}
\hline \multirow{2}{*}{ No. of components } & \multicolumn{2}{c}{ No. of binary variables required } \\
\cline { 2 - 3 } & SEN using separation tasks & SEN using key components \\
\hline 3 & 4 & 4 \\
4 & 11 & 10 \\
5 & 28 & 20 \\
6 & 46 & 35 \\
\hline
\end{tabular}

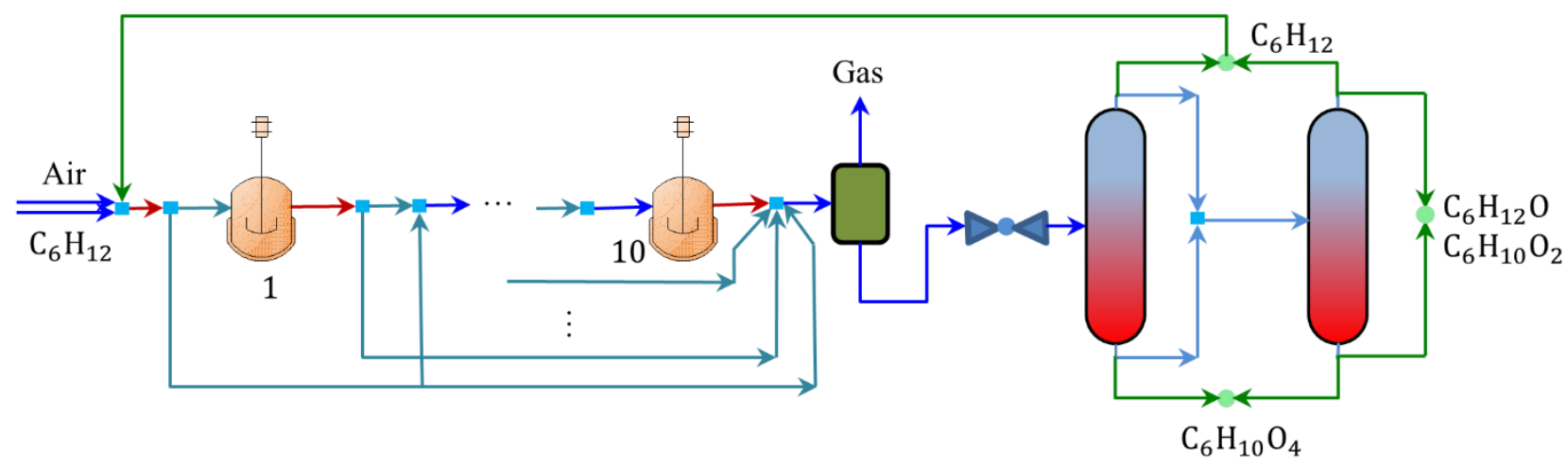

Figure S3 Superstructure for the cyclohexane oxidation process 


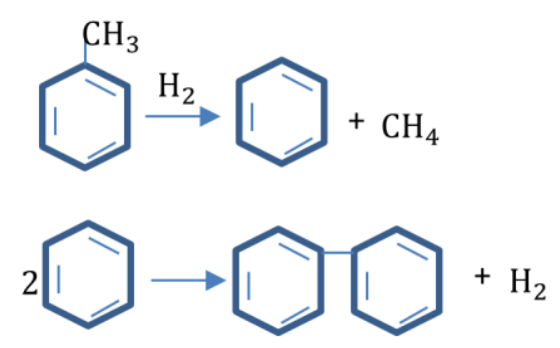

Figure S4 Reactions in the HDA process

\section{References}

1. Kocis, G. R.; Grossmann, I. E., Computational experience with dicopt solving MINLP problems in process systems engineering. Computers \& Chemical Engineering 1989, 13, (3), 307315.

2. Zhang, X.; Song, Z.; Zhou, T., Rigorous design of reaction-separation processes using disjunctive programming models. Computers \& Chemical Engineering 2018, 111, 16-26.

3. Kocis, G. R.; Grossmann, I. E., A modelling and decomposition strategy for the minlp optimization of process flowsheets. Computers \& Chemical Engineering 1989, 13, (7), 797-819. 4. Aspen Technology Inc., Aspen Properties User's Guide. In Technology, A., Ed. http://www.aspentech.com, 2015. 